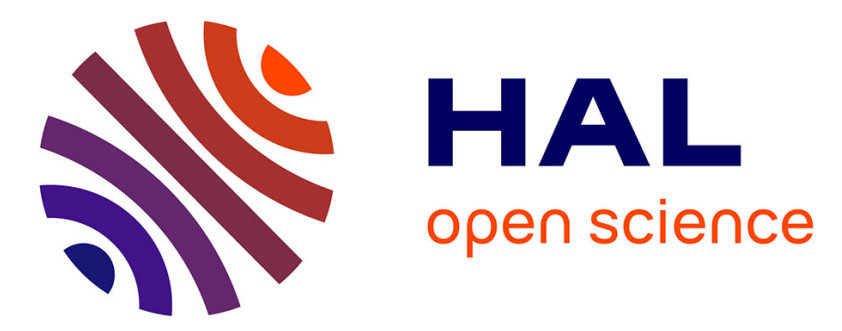

\title{
Differences in Photosensitized Release of VOCs from Illuminated Seawater versus Freshwater Surfaces
}

\author{
L. Stirchak, L. Abis, C. Kalalian, C. George, D. Donaldson
}

\section{To cite this version:}

L. Stirchak, L. Abis, C. Kalalian, C. George, D. Donaldson. Differences in Photosensitized Release of VOCs from Illuminated Seawater versus Freshwater Surfaces. ACS Earth and Space Chemistry, 2021, 5 (9), pp.2233-2242. 10.1021/acsearthspacechem.1c00063 . hal-03358677

\section{HAL Id: hal-03358677 https://hal.science/hal-03358677}

Submitted on 13 Oct 2021

HAL is a multi-disciplinary open access archive for the deposit and dissemination of scientific research documents, whether they are published or not. The documents may come from teaching and research institutions in France or abroad, or from public or private research centers.
L'archive ouverte pluridisciplinaire HAL, est destinée au dépôt et à la diffusion de documents scientifiques de niveau recherche, publiés ou non, émanant des établissements d'enseignement et de recherche français ou étrangers, des laboratoires publics ou privés. 


\section{Differences in photosensitized release of VOCs from illuminated seawater versus} freshwater surfaces

Laura T. Stirchak, ${ }^{1}$ Letizia Abis, ${ }^{2}$ Carmen Kalalian, ${ }^{2}$ Christian George, ${ }^{* 2}$ and D. James

Donaldson* ${ }^{1,3}$

1. Department of Chemistry, University of Toronto

2. Univ Lyon, Université Claude Bernard Lyon 1, CNRS, IRCELYON, F-69626, Villeurbanne, France

3. Department of Physical and Environmental Sciences, University of Toronto

*Authors for correspondence. Email: james.donaldson@utoronto.ca or

christian.george@ircelyon.univ-lyon1.fr

Keywords: VOCs, photochemistry, microlayer, sea-surface, PTR-MS,

Abstract: Recent studies have shown that photochemical reactions occurring at the air-water interface are a source of volatile organic compounds (VOCs) to the atmosphere. We report here the photosensitized formation of VOCs from illuminated freshwater and seawater mimics containing nonanoic acid (NA) and/or Suwannee River natural organic matter (SRNOM). Under an atmosphere of air, the total blank-corrected steady-state concentration of VOCs formed from illuminated seawater coated with nonanoic acid is somewhat smaller than that formed from freshwater, suggesting some differences in photochemical pathways for the two substrates. The total blank-corrected steady-state concentration of VOCs more than doubles from both freshwater and seawater NA-coated surfaces under nitrogen compared to air. The addition of SRNOM as a photosensitizer induces some photochemistry from the seawater sample under air, but no chemistry is seen with freshwater, or under nitrogen for either substrate. Adding SRNOM to the nonanoic acid-containing solutions roughly doubles the total steady-state concentration of VOCs emitted from both freshwater and seawater surfaces under air. The small differences in product formation for the two substrates implies some difference in the photochemical mechanisms operating in freshwater versus seawater, which may be due to the presence of halides and metals as well as $\mathrm{pH}$ differences between the two aqueous systems.

\section{Introduction}

The ocean-atmosphere interface covers $70 \%$ of the Earth's surface, and the chemistry that occurs there plays a crucial role in the exchange of species between the atmosphere and the hydrosphere. Heterogeneous chemistry taking place at the air-water interface is therefore of 
importance and interest. ${ }^{1,2}$ The presence of an organic coating, even as little as a sub-monolayer, at a water surface may alter the kinetics of heterogeneous reactions there, with the exact effect depending upon the composition of the monolayer. ${ }^{3-6}$ The air-water interface is also exposed to sunlight for large portions of time, suggesting the importance of heterogeneous photochemistry processes that may occur there. ${ }^{7}$

Recent studies have focused on understanding how the air-water interface influences the formation of volatile organic compounds (VOCs) in the aqueous phase and their release into the atmosphere. Field studies found evidence to suggest that the air-water interface is a source of VOCs, such as isoprene and formic acid, ${ }^{8-11}$ which suggests that a marine source of VOCs is more important than previously thought for the global VOC budget. ${ }^{12-14}$ In addition, it has been suggested that the type of aquatic environment (fresh versus saline) may influence the production of VOCs. ${ }^{15}$ Recent laboratory studies, ${ }^{16-24}$ using simplified aquatic environments, have shown that photochemistry at the air-water interface serves as a major abiotic source of functionalized VOCs, ${ }^{25-27}$ which has further implications towards the oxidative capacity of the atmosphere and the formation of secondary aerosols.

These laboratory studies have also highlighted the importance of a microlayer in the formation of the gas-phase products. The sea surface microlayer (SML) has been shown to play a crucial role as a boundary in the physical and chemical exchange between the ocean and the atmosphere. ${ }^{28,29}$ The SML is defined operationally as the uppermost $1 \mu \mathrm{m}$ to $1 \mathrm{~mm}$ of the surface of the ocean, and has been shown to persist at windspeeds up to $13 \mathrm{~ms}^{-1} .^{30,31}$ This microlayer, which covers a large portion of the ocean surface, is mainly composed of biogenic organic species such as lipids, hydrocarbons, proteins, and polysaccharides. ${ }^{32-38}$ Similarly, microlayers have been reported to be present on freshwater lakes and rivers, and the chemical composition of those organic microlayers are thought to be similar to the SML. ${ }^{39-42}$ For the purposes of this paper, microlayers on both fresh and seawater surfaces are referred to as SMLs.

Laboratory studies have commonly used fatty acids, such as nonanoic acid, 1-octanol, heptanoic acid, octanoic acid and hexanol, ${ }^{19-21,24}$ as SML proxies, because these compounds are found in sea surface waters at concentrations of $3-200 \mu \mathrm{gL}^{-1} \cdot 32,37,43$ One study compared the formation of VOCs from a proxy microlayer, using nonanoic acid, to an SML sample collected from Norway and found that there were limited differences between the gas-phase products from the two 
microlayers. ${ }^{21}$ Another study ${ }^{24}$ found that nonanoic acid was able to initiate its own photochemistry, highlighting the importance of the different chemical properties at the interface relative to the bulk aqueous phase. Overall, the illumination of these fatty acid microlayers produce functionalized VOCs at different concentrations, similar in composition to those detected in field studies. ${ }^{8-11,18,20,21,24}$

Laboratory and field studies have also noted that a photosensitizer, such as natural organic matter (NOM), is typically required to initiate the formation of VOCs at the interface, and may influence the concentration and identity of the VOCs produced. ${ }^{15,20,21,44} \mathrm{NOM}$ is an important component of surface waters, present at concentrations between 0.1 and $20 \mathrm{mgL}^{-1},{ }^{45-47}$ and is strongly enriched at the air-water interface, particularly when a microlayer is present. ${ }^{6,33,48}$ In the aquatic environment, NOM is photochemically active due to the presence of chromophoric species, as it can act as a photosensitizer via its excited triplet state, ${ }^{49-55}$ and the excited triplet state also leads to the formation of different reactive intermediates such as singlet oxygen $\left({ }^{1} \mathrm{O}_{2}\right)^{56-60}$ and the hydroxyl radical $\left(\mathrm{OH}^{*}\right) .{ }^{61-66}$ Additionally, it has been reported that riverine and oceanic natural organic matter exhibit different photosensitizing properties, ${ }^{67}$ which are highly variable due to the intrinsic link with local geology and biology. In particular, the activity of marine natural organic matter shows even day to day variability, related to its origin and the sampling procedures used. ${ }^{68,69}$ It has also been shown previously that the water composition, such as the presence of halides and different metals, alters the formation of the different reactive intermediates, ${ }^{70-76}$ thereby affecting the role that NOM plays in the photochemistry of surface waters. NOM can also participate in heterogenous, light-induced reactions at the interface with trace gases, such as $\mathrm{NO}_{2},{ }^{51}$ and ozone with chlorophyll. ${ }^{77}$ These studies suggest that photosensitized reactions at the interface could be particularly important in the production and transformation of volatile species, although the reaction mechanisms are poorly understood.

In this study, we investigated the total formation of VOCs from fresh and seawater mimics to understand whether there are differences in VOC formation linked to water compositional differences such as $\mathrm{pH}$ and the presence of halides, as well as differences when a surfactant and/or photosensitizer are present. Since the interactions between NOM and the SML are relatively unknown and there is a lot of variability in NOM samples, we used an available commercial standard, Suwannee River natural organic matter (SRNOM), to serve as a proxy 
photosensitizer and to obtain more reproducible experiments. Nonanoic acid was used as a proxy surfactant. By changing the chemical conditions of water bodies, we probe how the photochemical formation mechanisms of VOCs differ by reporting the blank corrected steadystate concentrations of VOCs formed. To the best of our knowledge, a direct comparison between the two water bodies has not been done previously.

\section{Methods}

Materials

The Natural Organic Matter sample used in this project was Suwannee River natural organic matter (SRNOM), purchased from the International Humic Substances Society (reference 2R101N) and used without any workup. Instant Ocean Sea Salt (IO), a synthetic sea salt used to make seawater solutions, was purchased from the company Instant Ocean (Product No. SS1510). The chemical composition of Instant Ocean has been reported previously by Langer et al. ${ }^{78}$ Nonanoic acid (Alfa Aesar; 97\% pure) was used as delivered. Solutions containing only Milli-Q deionized water or $40.1 \mathrm{gL}^{-1}$ IO in Milli-Q deionized water were used as blanks to identify any trace contamination from the aqueous substrates. Stock SRNOM solutions were made at a concentration of $10 \mathrm{mgL}^{-1}$. Freshwater mimics with $10 \mathrm{mgL}^{-1}$ SRNOM were made using Milli-Q deionized water (Elga Purelab Classic, 18.2 M ) while seawater solutions of $10 \mathrm{mgL}^{-1} \mathrm{SRNOM}$ were made with $40.1 \mathrm{gL}^{-1} \mathrm{IO}$. The freshwater mimics were at a $\mathrm{pH}$ of 5 while the seawater mimics were at a $\mathrm{pH}$ of 8.1, mimicking typical $\mathrm{pH}$ of natural aquatic samples. These $\mathrm{pHs}$ were true for the blanks as well as the mimics containing SRNOM and/or nonanoic acid.

\section{Quartz Cell Experiments: Instrument Set-Up Details}

A schematic of the experimental setup can be seen in Figure 1 below. The experiments were performed using a $14 \mathrm{~mL}, 5 \mathrm{~cm}$ pathlength quartz cell with an inlet at the top on either end (Starna, UK). The quartz cell was clamped in place $5 \mathrm{~cm}$ in front of the output of a Xenon lamp (150 W Xe, LOT-QuantumDesign, France) equipped with a water filter of $5 \mathrm{~cm}$ in length and a Pyrex filter to remove infrared radiation and short wavelengths $(\lambda<290 \mathrm{~nm})$. The experimental design was such that the photon flux entering the cell was very similar to solar radiation. More details are provided in Ciuraru et al., ${ }^{21}$ where in a similar experiment it is also shown that the location of the lamp does not limit production of VOCs. For each experiment, the cell was halffilled with $6 \mathrm{~mL}$ of the aqueous solution being studied; the resulting surface-to-volume ratio was 
approximately $1.4 \mathrm{~cm}^{-1}$. The experiments investigating the formation of VOCs from SRNOM only used either $10 \mathrm{mgL}^{-1} \mathrm{SRNOM}$ in pure DI water or $10 \mathrm{mgL}^{-1} \mathrm{SRNOM}$ in artificial seawater. For experiments using nonanoic acid, approximately $2.5 \mu \mathrm{L}$ of neat nonanoic acid was added to the water surface in the quartz cell using a micro-pipette, to reach a bulk concentration of $2 \mathrm{mM}$ nonanoic acid - sufficient to form a microlayer. The cell was gently stirred to promote the creation of the microlayer of acid over the aqueous surface, and then was left to sit for over 20 minutes before the experiment started. For the experiments involving SRNOM and nonanoic acid, $2.5 \mu \mathrm{L}$ of neat nonanoic acid was added to the water surface of solutions containing either $10 \mathrm{mgL}^{-1} \mathrm{SRNOM}$ in pure DI water or $10 \mathrm{mgL}^{-1} \mathrm{SRNOM}$ in artificial seawater. The temperature inside the quartz cell was not controlled during all experiments as a previous study by Bruggemann et al. ${ }^{42}$ determined that only a small increase in temperature would be seen during experiments using this set-up, and that a small increase in temperature would not induce a change in the VOC production.

The gases used for the experiments were either VOC-free compressed dry air (purified by means of a series of Donaldson purifying filters) or pure dry nitrogen passing through a Hydrocarbon Trap (Supelco, Supelpure ${ }^{\circledR}$ HC) prior to injection into the reactor. A gas flow was introduced into the quartz cell for all experiments at a flow rate of $200 \mathrm{sccm}$. A portion $-80 \mathrm{sccm}-$ of the outgoing gas flow from the quartz cell was sampled for analysis by a high-resolution proton transfer reaction mass spectrometer (PTR-TOF-MS 8000, Ionicon Analytik).

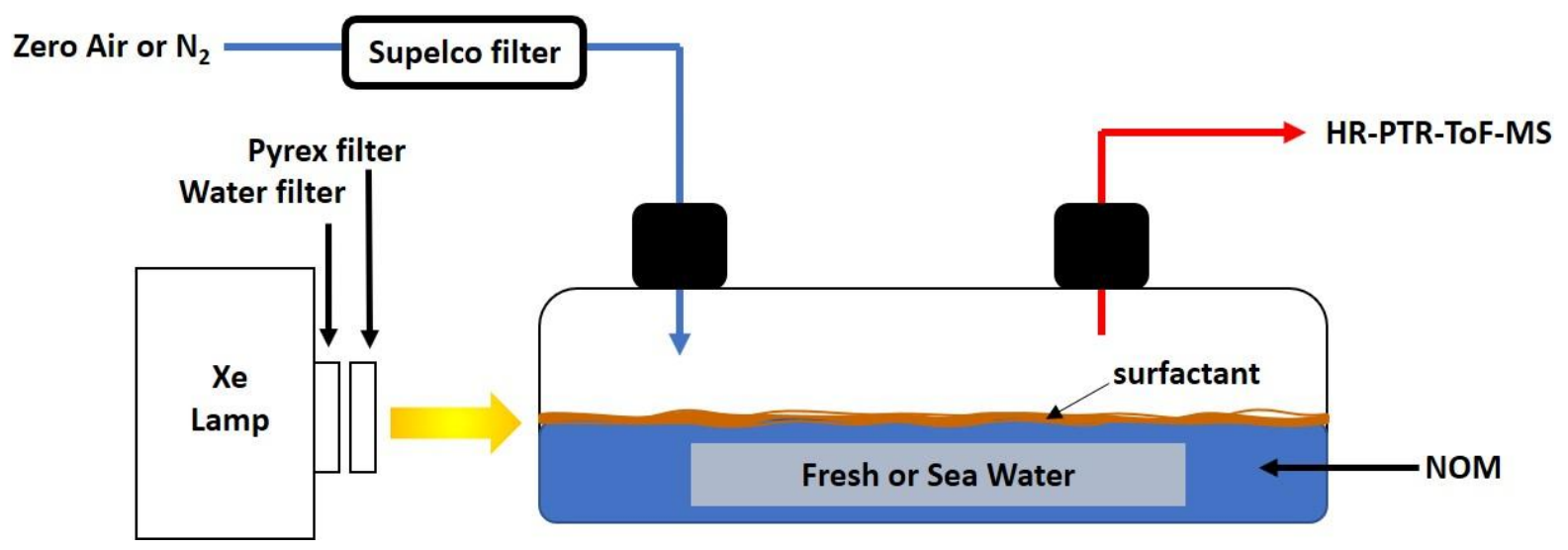

Figure 1: Schematic of experimental set-up.

HR-PTR-ToF-MS Analysis 
The quartz cell was connected to a Silcosteel inlet (1.5 $\mathrm{m}$ of $6 \mathrm{~mm}$ i.d.) of the HR-PTR-ToF-MS instrument using PTFA tubing, less than $5 \mathrm{~cm}$ in length, and PTFE connections. The sample inlet of the PTR-ToF-MS was kept at $60{ }^{\circ} \mathrm{C}$ during experiments to minimize the adsorption and condensation of VOCs. The $\mathrm{H}_{3} \mathrm{O}^{+}$reagent ions were generated using water vapor in a hollow cathode discharge ion source; this process has been described in detail elsewhere. ${ }^{79,80}$ The spectra were registered by co-adding single ToF-extractions between 1 and $10 \mathrm{~s}$, which lead to the resolution of approximately of $4500 \mathrm{~m} / \Delta \mathrm{m}$. The instrument was internally calibrated by fixing values for hydronium ion isotope $\left(\mathrm{H}_{3}{ }^{18} \mathrm{O}^{+} \mathrm{m} / \mathrm{z} 21.022\right)$ and protonated acetone $\left(\mathrm{C}_{3} \mathrm{H}_{7} \mathrm{O}^{+} \mathrm{m} / \mathrm{z}\right.$ 59.049). A calibration gas standard including 14 different VOCs with a concentration of $100 \pm$ $10 \mathrm{ppb}$ in nitrogen (TO-14A Aromatic Mix, Restek Corporation, Bellefonte, USA) was systematically used to evaluate the instrument performance, including mass resolution, mass accuracy, sensitivity, and relative mass-dependent transmission efficiency. Additional analytical details can be found in the SI.

\section{Experimental Details}

Experiments were done in freshwater and in seawater mimics, under both dry air and dry nitrogen. Background mass spectra were taken with an empty quartz cell (only air or $\mathrm{N}_{2}$ flowing through the cell), a pure water blank (referred to as a freshwater blank), and a seawater blank. All blanks were collected in triplicate; this was done once during the experiments under dry air and once under dry nitrogen. Three different systems were studied: in the first the sample only contained SRNOM, the second only contained nonanoic acid, and the third contained both SRNOM and nonanoic acid. All experiments were done in triplicate, with new solutions made for each replicate. The replicates for the blanks and all experiments with nonanoic acid showed good agreement. The first two replicates for the experiments with SRNOM-only showed good agreement, however the third replicate showed little to no formation of gas-phase products under dry air, for reasons that are unknown. The data from these third replicates were therefore not included in the data analysis.

Each individual experiment ran for 5 to 10 minutes, depending upon the type of experiment. The experiments without nonanoic acid were around 5 minutes in length, while the experiments with nonanoic acid took longer for product levels to stabilize, meaning they ran for 10 minutes. This difference in the time required for the product levels to stabilize is likely due to the presence of 
nonanoic acid, which lengthens the time required for the products to diffuse to the surface as well as transit time to the detector. Following stabilization of the PTR signals, the lamp was turned on, initiating an experiment. The light was turned off once the commonly monitored fragments of m/z 45 and/or m/z 59 plateaued. Since m/z 59 was not formed in all experiments, it was only monitored when it was photochemically produced from the illumination of the water surface. While m/z 45 was monitored during experiments, it was not included in the data work up due to concerns about potential acetaldehyde contamination during the experiments. The experiment ended once the product concentrations were stable at background concentrations for approximately 1 minute. In between experiments, the flow rate through the quartz cell was turned up to $500 \mathrm{sccm}$ to flush the system; this was done until no VOCs were detected by the HR-PTR-ToF-MS.

\section{Identification of Photoinduced Gas-Phase Products}

The analysis of the gas-phase products was performed using the $\mathrm{H}_{3} \mathrm{O}^{+}$ionization mode. The data treatment was done using the PTR Viewer 3.2.8 software (Ionicon Analytik, Innsbruck, Austria), where isotope $\mathrm{m} / \mathrm{z} 21.022$ was used to calculate the intensity of $\mathrm{H}_{3} \mathrm{O}^{+}$. Since no quantitative calibration was performed, concentrations reported are those obtained by the PTR Viewer software. Uncertainties on the absolute concentrations can be estimated to be about $30-40 \%$. The mass-to-charge ratios of the detected gas-phase species were identified for each experimental condition.

The data from the PTR Viewer software was transformed into time traces to monitor the evolution of gas-phase species that were formed upon illumination for each set of experiments. Shown in Figure 2 are representative time traces for seven of the commonly-observed gas-phase products produced photochemically in experiments with SRNOM in freshwater and seawater under air (Figure 2a and b), and experiments with nonanoic acid only in freshwater and seawater under air (Figure 2c and d). The $\mathrm{m} / \mathrm{z}$ ratios depicted in Figure 2 a-d are seven common species that were formed in all the experiments performed. The ratios are displayed to demonstrate the differences in the shape of the photochemical time traces between the different experiments. Tables S1 - S3 contain the full lists of mass-to-charge ratios of the products formed under the different experimental conditions. Additional information on the identification of gas-phase products and the resulting data analysis can also be found in the SI. 

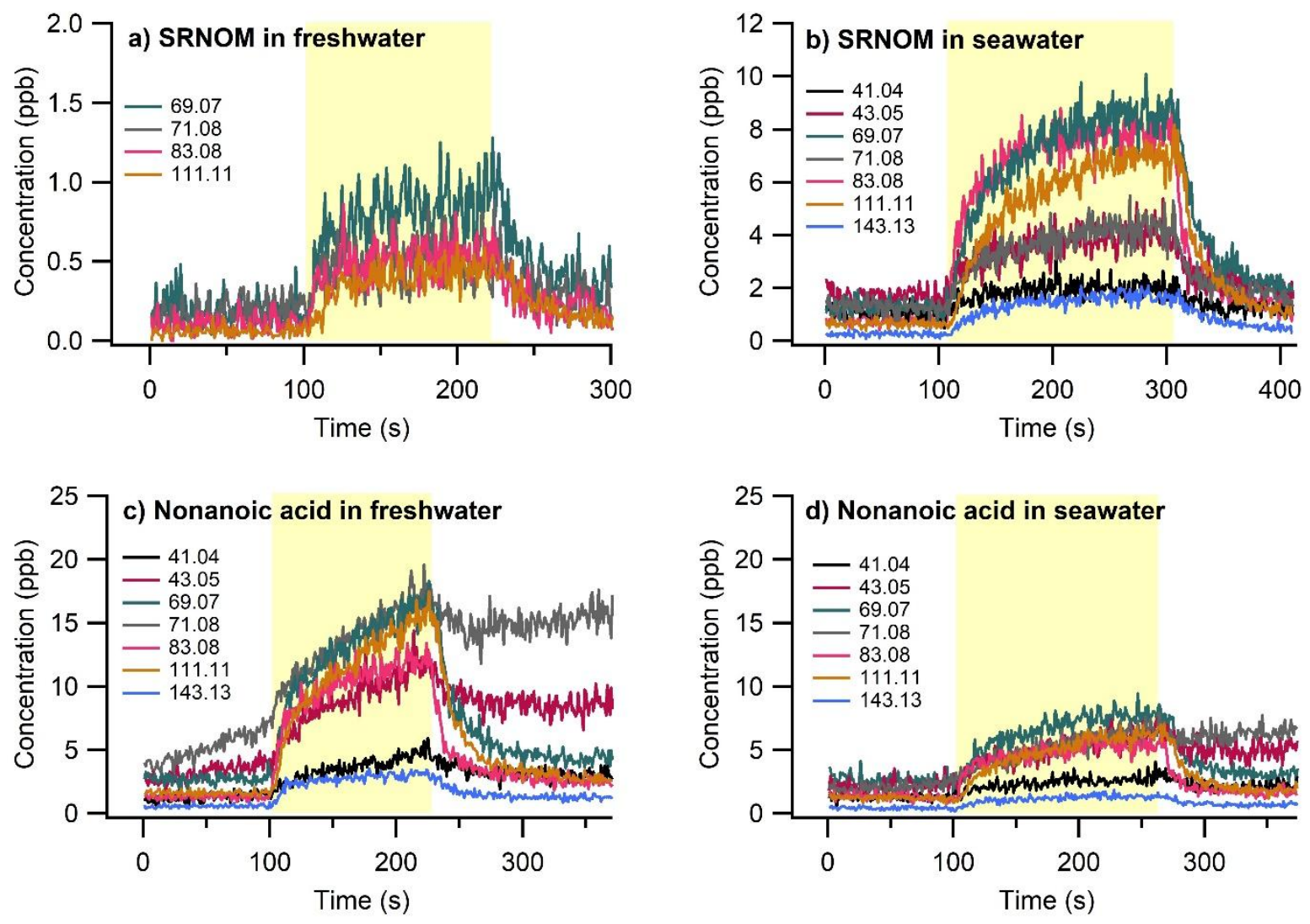

Figure 2: Select time traces for (a) $10 \mathrm{mgL}^{-1}$ SRNOM only in freshwater, (b) $10 \mathrm{mgL}^{-1}$ SRNOM only in seawater, (c) $2 \mathrm{mM}$ nonanoic acid only in freshwater, and (d) $2 \mathrm{mM}$ nonanoic acid only in seawater. All four experiments were run under air. In each case, the highlighted yellow region indicates the time during which the sample was illuminated during the experiment.

The plateauing of VOC time profiles is commonly observed in such experiments ${ }^{18,19,21,24}$ and depends upon whether the observed VOC species are first, second, or higher-generation products. The appearance of a steady state level for a particular gas-phase mass-to-charge ratio is due to a conjunction of processes, namely possible mass transport limitations in all phases, the sustained photochemical production, and various losses both in the aqueous and condensed phases. Previous work has shown that rich chemistry is also taking place in the aqueous phase ${ }^{18}$ and that analyzing only the gas phase, as done here, prevents any mass balance closure or detailed kinetics analysis from being completed. Accordingly, the analysis done below only focuses on the evolution of the observed gas-phase steady-state concentrations.

\section{Quantification of Results}

We fit each individual $\mathrm{m} / \mathrm{z}$ time trace in Origin using the following kinetic rate equation (Eqn 1), with $\mathrm{t}=0$ being the start time of illumunation: 


$$
y=A *\left(1-e^{-k t}\right)+b
$$

Eq. 1

where $\mathrm{A}$ is the steady state gas-phase concentration of VOCs formed under irradiation, $\mathrm{k}$ is the photochemical growth rate constant, and b is the offset from zero. Sample fits for two gas-phase products are shown in Figure S1. The steady-state concentrations (A-values) calculated for each $\mathrm{m} / \mathrm{z}$ were averaged over the replicates and the error was propagated using the reported standard deviations from the fitted equation. From these, the total steady-state concentration of VOCs from under each experiment was calculated by summing the averaged steady-state concentrations of the individual photochemically produced species. The error of the total steadystate concentration of VOCs was calculated by averaging the relative errors over each of the individual species, and then multiplying that average by the total steady-state VOC concentration. This was done for all traces from each set of experiments, including the blanks. Finally, to account for the trace formation of VOCs from the blanks (under air and $\mathrm{N}_{2}$ ), the total concentration of VOCs in the appropriate blank was subtracted from that in the specific experiment.

Additionally, the appearance rate for the gas-phase products represents a convolution of the rates of photochemistry, gas phase diffusion, different formation mechanisms, and transit time to the detector. For this reason the growth rate constants calculated from Equation 1 are not particularly meaningful here. However, the results of the fits, calculated using the same process as described above, are reported in the SI for completeness (Table S4).

\section{Results}

Photo-initiated formation of VOCs was observed from both aqueous substrates even in the absence of added photochemical agents, and so all steady-state concentrations reported and discussed here have been blank-corrected, in order to reflect any increase in VOC emission under the specific experimental conditions and remove any background noise.

\section{Photochemistry of SRNOM-Only in Freshwater versus Seawater}

First, we establish whether the SRNOM photosensitizer by itself produces VOCs under illumination when present in fresh- or seawater. NOM is known to act as a photosensitizer for other species in the aqueous environment, ${ }^{67}$ but whether or not it can initiate its own photochemical processes is less understood. Figure 3 displays the total emitted blank-corrected 
steady-state concentrations of VOCs, calculated as described above, from illuminated solutions containing only SRNOM with the freshwater experiments shown in red and the seawater experiments in blue.

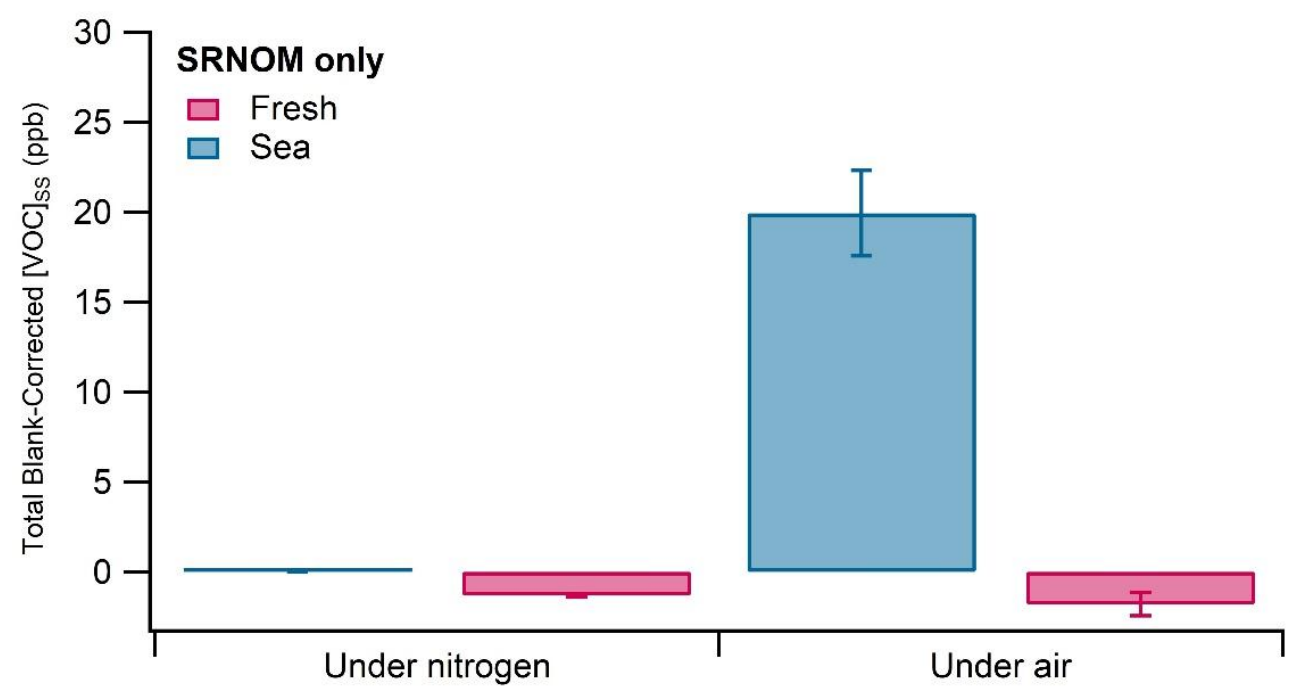

Figure 3: The total blank-corrected steady state concentrations (A-values) pulled from the kinetic growth fitting are shown for SRNOM only in freshwater (red) and seawater (blue). The experiments under nitrogen are shown on the left and the experiments under air are shown on the right. The error bars represent the error propagation of the standard deviation from the fitted equation.

The first important finding is that no gas-phase products are observed upon illumination of seawater or freshwater solutions under nitrogen with only SRNOM present, as shown in Figure 3. This observation implies that direct photodegradation of SRNOM does not lead to the formation of gas-phase species, either in seawater or freshwater. Very minute VOC concentrations were detected from the blanks and from the solutions containing SRNOM and were attributed to trace contamination. The apparent negative steady-state concentrations in Figure 3 are due to small variations between the blanks and the mimics.

The same experiments conducted under air (shown on the right side of Figure 3) show no VOC emission from the freshwater mimics, and a modest emission from the seawater mimics. There were again very minute concentrations detected from the freshwater blank and freshwater SRNOM mimic, which were attributed to trace contamination. For the seawater experiments, there were more VOC fragments detected from the SRNOM seawater mimic than the corresponding blank. Although we cannot rule out a symbiotic or collective effect of seawater components and oxygen on the photodegradation of SRNOM itself in seawater, there were no 
VOC fragments detected from the freshwater SRNOM-containing mimics that were not also seen from the seawater blank. This observation suggests that SRNOM is somehow photochemically active in seawater under air, promoting a greater amount of photochemistry than is due to just the trace contaminants observed in the blank experiments.

One potential reason for the difference between the freshwater and seawater observations may be interactions between SRNOM and seawater components, such as halide species and metal ions, opening up different chemical pathways as discussed in Stirchak et al. ${ }^{73}$ As a caveat to that hypothesis, we note that there was greater VOC emission (both number of fragments identified and their steady-state concentrations) seen from the illuminated seawater blank mimics (i.e., pure water containing instant ocean salts) than from the freshwater blank mimics (i.e., pure water), suggesting different contaminants present in the two water mimics. Nevertheless, the total steady-state concentration of VOCs emitted from SRNOM in seawater remains quite small, particularly when compared to the steady-state concentrations of the gas-phase species formed from the experiments with nonanoic acid.

\section{Photochemistry of Nonanoic Acid in Freshwater versus Seawater}

To understand any fresh vs. seawater differences in VOC production from the direct photochemistry of a nonanoic acid (NA) coating in the absence of a photosensitizer, experiments were run under nitrogen using a solution with a bulk concentration of $2 \mathrm{mM}$ NA, which gives rise to just over a monolayer of surface coverage. ${ }^{24}$ The freshwater experiments were done to replicate the study by Rossignol et al., which originally determined that VOCs were produced from the illumination of nonanoic acid on freshwater surfaces. ${ }^{24}$ These results are shown in Figure 4, with a complete list of the photochemically produced mass-to-charge ratios reported in Table S2. The freshwater results obtained here are in good agreement with those reported by Rossignol et al. ${ }^{24}$ 


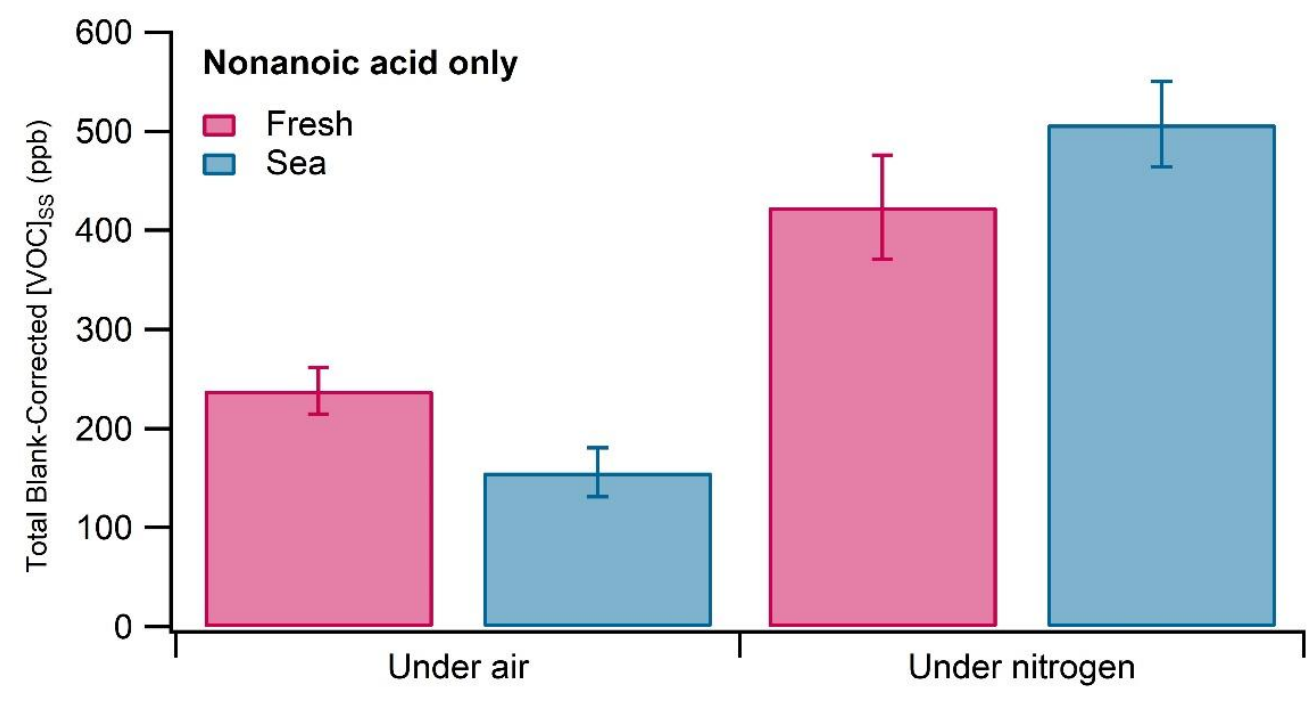

Figure 4: Plot showing the total blank-corrected steady-state concentrations) from the kinetic fits for nonanoic acid as a microlayer on freshwater and seawater mimics under air and under nitrogen. The freshwater experiments are shown in red while the seawater experiments are shown in blue. Note the very different scale from that of Figure 3. The error bars are the propagated error of the standard deviations from the fit. All these experiments were conducted in the absence of SRNOM.

Under nitrogen, the illumination of a NA coating on both freshwater and seawater mimics produces a noticeable amount of products, with the total steady-state concentration produced from freshwater slightly larger than the total steady-state concentration from seawater. This suggests that direct photochemistry of NA at both fresh- and seawater surfaces is an important source for VOCs, consistent with the mechanism reported by Rossignol et al. ${ }^{24}$ Results illustrated in Figure 4 demonstrate that under air, there is a definite reduction in the total steady-state concentration of gas-phase species emitted from both freshwater and seawater surfaces compared to the same surfaces under $\mathrm{N}_{2}$. The reduction is somewhat greater for seawater than the freshwater. Again consistent with the trend seen in Rossignol et al., ${ }^{24}$ this finding suggests that there are VOC formation mechanisms that operate under $\mathrm{N}_{2}$ that do not occur in the presence of oxygen. Additionally, or alternatively, the decrease in the total steady-state concentrations of VOCs under air from the freshwater and seawater mimics may be due to the formation of less volatile species, which cannot be detected by the PTR-MS.

\section{Photochemistry of Nonanoic Acid - SRNOM Mixtures in Freshwater versus Seawater}

To probe whether SRNOM acts as a photosensitizer for nonanoic acid chemistry, we ran experiments with $10 \mathrm{mgL}^{-1} \mathrm{SRNOM}$ added to the $2 \mathrm{mM}$ nonanoic acid solutions as a photosensitizer, in the freshwater and seawater mimics. Experiments were carried out under nitrogen and air; the nitrogen results are given in the SI for reference (Figure S2). Figure 5 
displays a comparison of the VOC emissions obtained from fresh- and seawater mimics with nonanoic acid coatings under air, in the absence (Figure 5b) and presence of (Figure 5a) SRNOM as a photosensitizer, and the full list of products is reported in Table S3. Overall, the addition of SRNOM as a photosensitizer to the nonanoic acid-containing solutions gives rise to an approximately factor-of-two increase in the total steady-state concentrations of gas-phase products from both freshwater and seawater solutions. This suggests that the addition of SRNOM as a photosensitizer may change the photochemical formation mechanisms of the gas-phase species. Interestingly, there is no striking difference in the total steady-state concentrations of VOCs emitted between the freshwater and seawater experiments, which contrasts with the results from the experiments which looked at only nonanoic acid.
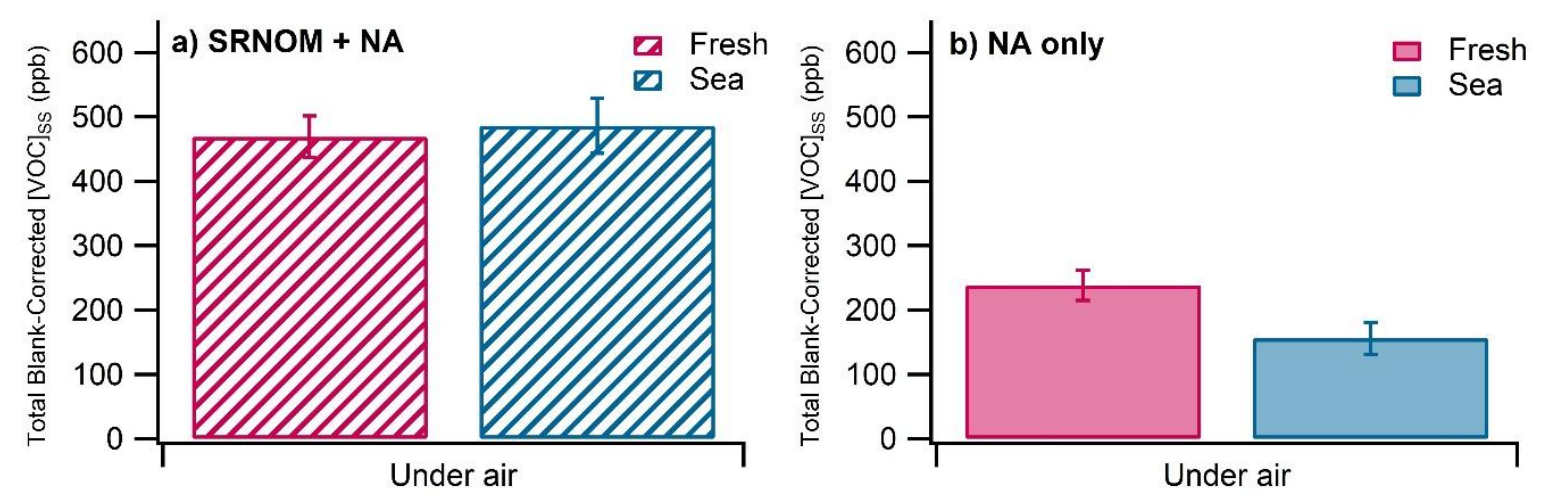

Figure 5: On the left (a) is a plot showing the total blank-corrected steady-state concentrations from the kinetic fits for SRNOM added to the nonanoic acid freshwater and seawater mimics under air. On the right (b), the results for the NA-only experiments are reproduced from Figure 4. The experiments done in freshwater are in red while the experiments in seawater are shown in blue. The error bars are the propagated error of the standard deviations from the fit.

\section{Discussion}

\section{Experiments with SRNOM Only}

Illumination under air of artificial seawater containing SRNOM showed evidence of photosensitized chemistry of very small steady-state concentrations of gas-phase species. Since NOM photochemistry is thought to be mediated through the triplet state, ${ }^{49,81-83}$ seawater components may well alter the triplet state chemistry of SRNOM. The requirement for oxygen to be present for the formation of VOCs suggests a potential mechanism. Interactions between NOM and ionic species in seawater has been shown to alter the formation of different reactive intermediates such as ${ }^{3} \mathrm{NOM}^{*}$ and ${ }^{1} \mathrm{O}_{2} \cdot{ }^{72,73,75,84}$ It has been reported previously that the formation rates of ${ }^{3} \mathrm{SRNOM}^{*}$ decrease in seawater due to the formation of SRNOM-Mg complexes, ${ }^{73,75}$ 
which leads in turn to a decrease in the formation of singlet oxygen. However, there may be an increase in other reactive oxygen species, such as superoxide $\left(\mathrm{O}_{2}{ }^{-}\right)$or $\mathrm{OH}^{\cdot}{ }^{85-87}$ due to ${ }^{3} \mathrm{SRNOM}^{*}$ quenching by seawater components, which could lead to the formation of VOCs.

Alternately, the high concentration of halides, and other ionic species, in seawater has also been shown to promote intersystem crossing, which might increase the steady-state concentration of ${ }^{3}$ SRNOM. ${ }^{71,88}$ In turn, this higher excited triplet concentration may give rise to the increased formation of singlet oxygen and other reactive oxygenated species (ROS) via reaction with atmospheric $\mathrm{O}_{2}$ at the aqueous surface. Grossman et al. ${ }^{70}$ found that the photodegradation of anthracene was increased in the presence of halides relative to freshwater degradation rates, and that this increase was due to the increased formation of singlet oxygen in the presence of halides. This mechanism would explain why no gas-phase products were produced under nitrogen from the freshwater and seawater substrates.

\section{Experiments with Nonanoic Acid}

Rossignol et al. ${ }^{24}$ reported the formation of gas-phase saturated and unsaturated aldehydes from the illumination of nonanoic acid present at the surface of freshwater and showed that this chemistry occurs because in highly concentrated systems, such as a compressed surface layer, nonanoic acid weakly absorbs at actinic flux wavelengths, allowing the formation of the excited triplet state followed by interface-specific radical initiated reactions. The authors proposed that if the excited triplet behaves as a traditional photosensitizer, it can initiate an intermolecular Norrish type II reaction, as it can abstract a proton from an adjacent NA molecule to form a diol radical and an acid radical. The triplet could also undergo homolytic cleavage. ${ }^{24}$ Both of these proposed mechanisms can also occur in deoxygenated environments, which could explain the formation of gas-phase species that we see under $\mathrm{N}_{2}$ when nonanoic acid is present. In oxygenated environments however, the excited state triplet mechanisms appear to compete with an $\mathrm{H}$-abstraction mechanism which is initiated by the hydroxyl radical. The $\mathrm{H}$-abstraction mechanism favors oxygen addition, leading to oxidation products and aldehydes which is consistent with results reported from studies using nonanoic acid and 1-octanol as surfactants. ${ }^{19,24}$

It is expected that these same formation mechanisms proposed by Rossignol et al. ${ }^{24}$ would occur when nonanoic acid is present as a microlayer on the seawater surface. In addition, the formation 
mechanisms of VOCs involving ${ }^{3} \mathrm{NOM}^{*}$ and $\mathrm{X}^{-}$, as previously described, would also be expected to occur. However, the total concentration of VOCs formed from nonanoic acid on seawater was lower than from freshwater. One possibility for the lower production of VOCs observed is that the seawater photochemistry produces more soluble products at the expense of gas-phase compounds, perhaps due to the participation of halogen radicals, formed via halide oxidation. Since we do not analyze the solution phase, we can neither confirm nor exclude this hypothesis.

There are two further explanations for why there is a lower concentration of VOCs formed from the illumination of nonanoic acid on seawater than on freshwater. First, it is likely that nonanoic acid has different solubilities at the surface in the two water systems which would affect the formation of gas-phase species. Ciuraru et al. ${ }^{20}$ found that the flux of isoprene decreased as a function of $\mathrm{pH}$, which the authors attributed to the increasing solubility of nonanoic acid. In another study by Ciuaru et $\mathrm{al}^{21}$ it was determined that the formation of VOCs can only occur at the interface, not in the bulk. As nonanoic acid becomes more soluble at a higher $\mathrm{pH}$, there will be less surface coverage and therefore less interfacial chemistry will occur, leading to fewer gasphase species. Our seawater experiments were done at a $\mathrm{pH}$ of 8 , at which point nonanoic acid is completely dissociated. The negative charge on the end group will make it more likely to be soluble, as well as lead to sparser surface coverage due to repulsive interactions between the charged headgroups. Therefore, at the higher $\mathrm{pH}$ in seawater, nonanoic acid will not fully cover the surface, which may lead to lower steady-state concentrations of gas-phase products detected by the PTR-MS.

It is also possible that the interactions between nonanoic acid at the interface and the components of seawater, such as halides and metal ions, leads to different formation mechanisms for gasphase products from seawater. Lee et $\mathrm{al}^{89}$ found that the surface propensity of iodide and bromide depended upon the identity of the different organic surfactants. They found that 1butanol enhanced the presence of halides at the surface while butyric acid led to a reduction of interfacial halide ion density. The authors attribute this difference to the head groups, which can change the electrostatic interactions at the interface. This would imply that at higher $\mathrm{pHs}$, the charged headgroups on the dissociated nonanoic acid would reduce the presence of halides at the interface, which may have led to the reduction in photochemistry from seawater when oxygen is 
present. Huang et al, ${ }^{90}$ in contrast, found that Fe(III) enhanced the formation of VOCs from nonanoic acid. This could be due to the fact that Fe(III) rapidly quenches ${ }^{1} \mathrm{NOM}^{*},{ }^{91-93}$ which could increase the importance of intersystem crossing, leading to a greater ${ }^{3} \mathrm{NOM}^{*}$ concentration. However, the experiments were done at acidic $\mathrm{pH}$, which would cause a greater surface coverage with NA than in our experiments at $\mathrm{pH} 8$, thereby changing the distribution of results.

It has been shown that when an organic-soluble photosensitizer and an organic surfactant are present together in a sample, the photosensitizer will migrate to the interfacial surfactant thereby changing the distribution of products because the formation mechanisms are changing. ${ }^{18,23}$ This matches the results from our experiments, as the addition of SRNOM resulted in greatly increased VOC formation from both seawater and freshwater under air. Previous studies have seen that the addition of either a surfactant ${ }^{23}$ or a photosensitizer ${ }^{18,20}$ has led to some products being more favored than others. Both studies argued that these trends could be explained by competition for $\mathrm{H}$-abstraction between the excited photosensitizer and the excited nonanoic acid. The present results suggest that this competition may occur in both freshwater and seawater, as similar trends were observed for favored products in the presence of the photosensitizer. Although we do not confirm the identities of the products formed in these experiments, previous studies have reported the formation of isoprene, ${ }^{20}$ alkenes, ${ }^{15,18,21}$ dienes, ${ }^{94}$ and C2-C9 unsaturated aldehydes. $^{21,24}$ Finally, the production of gas-phase products from nonanoic acid, with and without SRNOM, is not completely shut down in deoxygenated systems. The production of alkenes, such as $\mathrm{C}_{4} \mathrm{H}_{8}$ and $\mathrm{C}_{5} \mathrm{H}_{10}$, under nitrogen has been reported previously and it is thought that these species are likely formed via the degradation of nonanoic acid. ${ }^{18,24}$

\section{Conclusions}

The abiotic production of VOCs at the air-sea interface has been suggested as potentially a major source of VOCs depending on seasons and locations ${ }^{24,42,44}$ This hypothesis is mainly based on data obtained from the air-water interface of freshwater samples, extrapolated to marine conditions. Here we demonstrate that this hypothesis is valid, as we detect VOCs from illuminated freshwater and seawater surfaces. We also unraveled differences in the formation of VOCs that are seemingly tied to the presence of halides and the higher $\mathrm{pH}$ in the seawater samples, which introduce additional formation mechanisms and alter the physical properties of the sea surface microlayer. Additional systematic studies which investigate the formation of 
VOCs as a function of salinity, metal composition, and $\mathrm{pH}$ should be completed. This will allow for the development of proposed reaction mechanisms for VOCs from different aquatic environments. Those studies should also determine the actual identities of the different gas-phase species formed to really probe the mechanistic differences. In addition to gas-phase species, it is necessary to investigate the aqueous phase products as it has been shown that highly oxygenated species are produced from illuminated mimics with a surfactant in the presence and absence of a

photosensitizer, and that these species are detected in the bulk aqueous phase. ${ }^{18,24,95}$ The presence of halides may increase the reactivity of the system, which could form more soluble products. Therefore, the decrease in gas-phase products reported in this study may suggest that more soluble, and possibly more oxygenated, products are being formed; we just cannot detect them with the PTR-MS. From freshwater to seawater environments, there is a rich chemistry occurring at the air-water interface which changes the pattern of VOC emissions.

\section{Acknowledgments}

This work was funded by NSERC, to whom we are grateful. LTS thanks the Department of Chemistry at the University of Toronto for a Special Opportunity Graduate Travel Fellowship. This project was also supported by the ANR (project ANR-16-CE01-0013).

\section{References}

1. Clifford, D., Donaldson, D. J., Brigante, M., D’Anna, B. \& George, C. Reactive uptake of ozone by chlorophyll at aqueous surfaces. Environ. Sci. Technol. 42, 1138-1143 (2008).

2. Voss, L. F., Bazerbashi, M. F., Beekman, C. P., Hadad, C. M. \& Allen, H. C. Oxidation of oleic acid at air/liquid interfaces. J. Geophys. Res. Atmos. 112, 1-9 (2007).

3. Mmereki, B. T., Donaldson, D. J., Gilman, J. B., Eliason, T. L. \& Vaida, V. Kinetics and products of the reaction of gas-phase ozone with anthracene adsorbed at the air-aqueous interface. Atmos. Environ. 38, 6091-6103 (2004).

4. Mmereki, B. T. \& Donaldson, D. J. Direct Observation of the Kinetics of an Atmospherically Important Reaction at the Air-Aqueous Interface. J. Phys. Chem. A 107, 11038-11042 (2003).

5. Soule, M. C. K., Blower, P. G. \& Richmond, G. L. Effects of atmospherically important 
solvated ions on organic acid adsorption at the surface of aqueous solutions. J. Phys. Chem. B 111, 13703-13713 (2007).

6. Donaldson, D. \& Vaida, V. The Influence of Organic Films at the Air- Aqueous Boundary on Atmospheric Processes. Chem. Rev 106, 1445-1461 (2006).

7. Liss, P. S. \& Duce, R. A. The Sea Surface and Global Change. (Cambridge University Press, 2005).

8. Kieber, D. J. \& Mopper, K. Photochemical formation of glyoxylic and pyruvic acids in seawater. Science (80-. ). 21, 135-149 (1987).

9. Zhou, X. \& Mopper, K. Photochemical production of low-molecular-weight carbonyl compounds in seawater and surface microlayer and their air-sea exchange. Mar. Chem. 56, 201-213 (1997).

10. Zhu, Y. \& Kieber, D. J. Concentrations and Photochemistry of Acetaldehyde, Glyoxal, and Methylglyoxal in the Northwest Atlantic Ocean. Environ. Sci. Technol. 53, 95129521 (2019).

11. Wang, S. et al. Atmospheric Acetaldehyde: Importance of Air-Sea Exchange and a Missing Source in the Remote Troposphere. Geophys. Res. Lett. 46, 5601-5613 (2019).

12. Kansal, A. Sources and reactivity of NMHCs and VOCs in the atmosphere: A review. $J$. Hazard. Mater. 166, 17-26 (2009).

13. El Haddad, I. et al. Towards a better understanding of the origins, chemical composition and aging of oxygenated organic aerosols: Case study of a Mediterranean industrialized environment, Marseille. Atmos. Chem. Phys. 13, 7875-7894 (2013).

14. Rinaldi, M. et al. Primary and Secondary Organic Marine Aerosol and Oceanic Biological Activity: Recent Results and New Perspectives for Future Studies. Adv. Meteorol. 2010, $1-10$ (2010).

15. Riemer, D. D., Milne, P. J., Zika, R. G. \& Pos, W. H. Photoproduction of nonmethane hydrocarbons (NMHCs) in seawater. Mar. Chem. 71, 177-198 (2000). 
16. Brüggemann, M., Hayeck, N. \& George, C. Interfacial photochemistry at the ocean surface is a global source of organic vapors and aerosols. Nat. Commun. 9, 1-8 (2018).

17. Chiu, R. et al. UV photochemistry of carboxylic acids at the air-sea boundary: A relevant source of glyoxal and other oxygenated VOC in the marine atmosphere. Geophys. Res. Lett. 44, 1079-1087 (2017).

18. Tinel, L. et al. Mechanistic Insights on the Photosensitized Chemistry of a Fatty Acid at the Air/Water Interface. Environ. Sci. Technol. 50, 11041-11048 (2016).

19. Fu, H. et al. Photosensitized Production of Atmospherically Reactive Organic Compounds at the Air/Aqueous Interface. J. Am. Chem. Soc. 137, 8348-8351 (2015).

20. Ciuraru, R. et al. Unravelling New Processes at Interfaces: Photochemical Isoprene Production at the Sea Surface. Environ. Sci. Technol. 49, 13199-13205 (2015).

21. Ciuraru, R. et al. Photosensitized production of functionalized and unsaturated organic compounds at the air-sea interface. Sci. Rep. 5, 1-10 (2015).

22. Zhou, S. et al. Formation of gas-phase carbonyls from heterogeneous oxidation of polyunsaturated fatty acids at the air-water interface and of the sea surface microlayer. Atmos. Chem. Phys. 14, 1371-1384 (2014).

23. Roveretto, M. et al. Real-Time Detection of Gas-Phase Organohalogens from Aqueous Photochemistry Using Orbitrap Mass Spectrometry. ACS Earth Sp. Chem. 3, 329-334 (2019).

24. Rossignol, S. et al. Atmospheric photochemistry at a fatty acid-coated air-water interface. Science (80-. ). 353, 699-702 (2016).

25. Alpert, P. A. et al. Fatty Acid Surfactant Photochemistry Results in New Particle Formation. Sci. Rep. 7, 1-11 (2017).

26. Schneider, S. R., Collins, D. B., Lim, C. Y., Zhu, L. \& Abbatt, J. P. D. Formation of Secondary Organic Aerosol from the Heterogeneous Oxidation by Ozone of a Phytoplankton Culture. ACS Earth Sp. Chem. 3, 2298-2306 (2019). 
27. Novak, G. A. \& Bertram, T. H. Reactive VOC Production from Photochemical and Heterogeneous Reactions Occurring at the Air-Ocean Interface. Acc. Chem. Res. 53, 1014-1023 (2020).

28. Donaldson, D. J. \& George, C. Sea-surface chemistry and its impact on the marine boundary layer. Environ. Sci. Technol. 46, 10385-9 (2012).

29. Carpenter, L. J. \& Nightingale, P. D. Chemistry and Release of Gases from the Surface Ocean. Chem. Rev. 115, 4015-4034 (2015).

30. Wurl, O., Ekau, W., Landing, W. M. \& Zappa, C. J. Sea surface microlayer in a changing ocean - A perspective. Elementa 5, (2017).

31. Sabbaghzadeh, B., Upstill- Goddard, R. C., Beale, R., Pereira, R. \& Nightingale, P. D. The Atlantic Ocean surface microlayer from $50^{\circ} \mathrm{N}$ to $50^{\circ} \mathrm{S}$ is ubiquitously enriched in surfactants at wind speeds up to 13 m s-1. Geophys. Res. Lett. 44, 2852-2858 (2017).

32. Momzikoff, A. et al. Field study of the chemical characterization of the upper ocean surface using various samplers. Limnol. Oceanogr. Methods 2, 374-386 (2004).

33. Carlson, D. J. Dissolved organic materials in surface microlayers: Temporal and spatial variability and relation to sea state. Limnol. Oceanogr. 28, 415-431 (1983).

34. Engel, A. et al. The ocean's vital skin: Toward an integrated understanding of the sea surface microlayer. Front. Mar. Sci. 4, 1-14 (2017).

35. King, L., Roberts, I. J., Tinel, L. \& Carpenter, L. J. The Determination of Surfactants at the Sea Surface. Ocean Sci. Discuss. 1-30 (2019). doi:10.5194/os-2019-87

36. Miranda, M. L. et al. Influence of solar radiation on biogeochemical parameters and fluorescent dissolved organic matter (FDOM) in the sea surface microlayer of the southern coastal North Sea. Elem Sci Anth 6, 1-17 (2018).

37. Gašparović, B., Plavšić, M., Ćosović, B. \& Saliot, A. Organic matter characterization in the sea surface microlayers in the subarctic Norwegian fjords region. Mar. Chem. 105, 114 (2007). 
38. Williams, P. M. et al. Chemical and microbiological studies of sea-surface films in the Southern Gulf of California and off the West Coast of Baja California. Mar. Chem. 19, 17-98 (1986).

39. Hatcher, R. F. \& Parker, B. C. Microbiological and chemical enrichment of freshwater surface microlayers relative to the bulk subsurface water. Can. J. Microbiol. 20, 10511057 (1974).

40. Andren, A. W., Elzerman, A. W. \& Armstrong, D. E. Chemical and Physical Aspects of Surface Organic Microlayers in Freshwater Lakes. J. Great Lakes Res. 2, 101-110 (1976).

41. Södergren, A. Role of aquatic surface microlayer in the dynamics of nutrients and organic compounds in lakes, with implications for their ecotones. Nutr. Dyn. Retent. Land/Water Ecotones Lowl. Temp. Lakes Rivers 217-225 (1993). doi:10.1007/978-94-011-1602-2_24

42. Brüggemann, M. et al. Interfacial photochemistry of biogenic surfactants: A major source of abiotic volatile organic compounds. Faraday Discuss. 200, 59-74 (2017).

43. Parrish, C. C., Thompson, R. J. \& Deibel, D. Lipid classes and fatty acids in plankton and settling matter during the spring bloom in a cold ocean coastal environment. Mar. Ecol. Prog. Ser. 286, 57-68 (2005).

44. Mungall, E. L. et al. Microlayer source of oxygenated volatile organic compounds in the summertime marine Arctic boundary layer. Proc. Natl. Acad. Sci. 114, 6203-6208 (2017).

45. Thurman, E. M. Organic geochemistry of natural waters. (Kluwer, 1985).

46. Hertkorn, N., Harir, M., Koch, B. P., Michalke, B. \& Schmitt-Kopplin, P. High-field NMR spectroscopy and FTICR mass spectrometry: Powerful discovery tools for the molecular level characterization of marine dissolved organic matter. Biogeosciences 10, 1583-1624 (2013).

47. Clark, C. D. \& Zika, R. G. Introduction. in Marine Chemistry (ed. Wangersky, P. J.) 1-33 (Springer, 2000).

48. Carlson, D. J. \& Mayer, L. M. Enrichment of dissolved phenolic material in the surface 
microlayer of coastal waters. Nature 286, 482-483 (1980).

49. Canonica, S., Jans, U., Stemmler, K. \& Hoigné, J. Transformation kinetics of phenols in water: photosensitization by dissolved natural organic material and aromatic ketones. Environ. Sci. Technol. 29, 1822-1831 (1995).

50. Chin, Y. P., Miller, P. L., Zeng, L., Cawley, K. \& Weavers, L. K. Photosensitized degradation of bisphenol A by dissolved organic matter. Environ. Sci. Technol. 38, 58885894 (2004).

51. Stemmler, K., Ammann, M., Donders, C., Kleffmann, J. \& George, C. Photosensitized reduction of nitrogen dioxide on humic acid as a source of nitrous acid. Nature 440, 195198 (2006).

52. Wenk, J., Aeschbacher, M., Sander, M., Gunten, U. Von \& Canonica, S. Photosensitizing and inhibitory effects of ozonated dissolved organic matter on triplet-induced contaminant transformation. Environ. Sci. Technol. 49, 8541-8549 (2015).

53. Calza, P., Vione, D. \& Minero, C. The role of humic and fulvic acids in the phototransformation of phenolic compounds in seawater. Sci. Total Environ. 493, 411418 (2014).

54. Canonica, S. \& Freiburghaus, M. Electron-rich phenols for probing the photochemical reactivity of freshwaters. Environ. Sci. Technol. 35, 690-695 (2001).

55. Wenk, J., Eustis, S. N., McNeill, K. \& Canonica, S. SI: Quenching of excited triplet states by dissolved natural organic matter. Environ. Sci. Technol. 47, 12802-10 (2013).

56. Haag, W. R. \& Hoigné, J. Singlet oxygen in surface waters. 3. Photochemical formation and steady-state concentrations in various types of waters. Environ. Sci. Technol. 20, 341348 (1986).

57. Haag, W. R., Hoigné, J., Gassman, E. \& Braun, A. M. Singlet oxygen in surface watersPart 1: furfuryl alcohol as a trapping agent. Chemosphere 13, 631-640 (1984).

58. Sharpless, C. M. Lifetimes of triplet dissolved natural organic matter (DOM) and the 
effect of $\mathrm{NaBH} 4$ reduction on singlet oxygen quantum yields: Implications for DOM photophysics. Environ. Sci. Technol. 46, 4466-4473 (2012).

59. Fede, A. \& Grannas, A. M. Photochemical production of singlet oxygen from dissolved organic matter in ice. Environ. Sci. Technol. 49, 12808-12815 (2015).

60. Dalrymple, R. M., Carfagno, A. K. \& Sharpless, C. M. Correlations between dissolved organic matter optical properties and quantum yields of singlet oxygen and hydrogen peroxide. Environ. Sci. Technol. 44, 5824-5829 (2010).

61. Sur, B. et al. Formation of hydroxyl radicals by irradiated 1-nitronaphthalene (1NN): oxidation of hydroxyl ions and water by the 1NN triplet state. Photochem. Photobiol. Sci. 10, 1817-24 (2011).

62. Sun, L., Chen, H., Abdulla, H. A. \& Mopper, K. Estimating hydroxyl radical photochemical formation rates in natural waters during long-term laboratory irradiation experiments. Environ. Sci. Process. Impacts 16, 757-763 (2014).

63. Vione, D. et al. Sources and sinks of hydroxyl radicals upon irradiation of natural water samples. Environ. Sci. Technol. 40, 3775-3781 (2006).

64. McKay, G. \& Rosario-Ortiz, F. L. Temperature dependence of the photochemical formation of hydroxyl radical from dissolved organic matter. Environ. Sci. Technol. 49, 4147-4154 (2015).

65. Page, S. E., Logan, J. R., Cory, R. M. \& McNeill, K. Evidence for dissolved organic matter as the primary source and sink of photochemically produced hydroxyl radical in arctic surface waters. Environ. Sci. Process. Impacts 16, 807-822 (2014).

66. McKay, G., Couch, K. D., Mezyk, S. P. \& Rosario-Ortiz, F. L. Investigation of the coupled effects of molecular weight and charge-transfer interactions on the optical and photochemical properties of dissolved organic matter. Environ. Sci. Technol. 50, 80938102 (2016).

67. Trueblood, J. V. et al. Shedding Light on Photosensitized Reactions within MarineRelevant Organic Thin Films. ACS Earth Sp. Chem. 3, 1614-1623 (2019). 
68. Van Pinxteren, M. et al. Marine organic matter in the remote environment of the Cape Verde islands-an introduction and overview to the MarParCloud campaign. Atmos. Chem. Phys. 20, 6921-6951 (2020).

69. Karimova, N. V., Alves, M. R., Luo, M., Grassian, V. H. \& Gerber, R. B. Toward a microscopic model of light absorbing dissolved organic compounds in aqueous environments: Theoretical and experimental study. Phys. Chem. Chem. Phys. 23, 1048710497 (2021).

70. Grossman, J. N., Kowal, S. F., Stubbs, A. D., Cawley, C. N. \& Kahan, T. F. Anthracene and Pyrene Photooxidation Kinetics in Saltwater Environments. ACS Earth Sp. Chem. 3, 2695-2703 (2019).

71. Glover, C. M. \& Rosario-Ortiz, F. L. Impact of halides on the photoproduction of reactive intermediates from organic matter. Environ. Sci. Technol. 47, 13949-13956 (2013).

72. Parker, K. M., Pignatello, J. J. \& Mitch, W. A. Influence of ionic strength on triplet-state natural organic matter loss by energy transfer and electron transfer pathways. Environ. Sci. Technol. 47, 10987-10994 (2013).

73. Stirchak, L. T., Moor, K. J., McNeill, K. \& Donaldson, D. J. Differences in photochemistry between seawater and freshwater for two natural organic matter samples. Environ. Sci. Process. Impacts 21, 28-39 (2019).

74. Pan, Y., Garg, S., Waite, T. D. \& Yang, X. Copper Inhibition of Triplet-Induced Reactions Involving Natural Organic Matter. Environ. Sci. Technol. 52, 2742-2750 (2018).

75. Wan, D., Sharma, V. K., Liu, L., Zuo, Y. \& Chen, Y. Mechanistic Insight into the Effect of Metal Ions on Photogeneration of Reactive Species from Dissolved Organic Matter. Environ. Sci. Technol. 53, 5778-5786 (2019).

76. al Housari, F., Vione, D., Chiron, S. \& Barbati, S. Reactive photoinduced species in estuarine waters. Characterization of hydroxyl radical, singlet oxygen and dissolved organic matter triplet state in natural oxidation processes. Photochem. Photobiol. Sci. 9, 
78-86 (2010).

77. Reeser, D. I. et al. Photoenhanced reaction of ozone with chlorophyll at the seawater surface. J. Phys. Chem. C 113, 2071-2077 (2009).

78. Langer, S., Pemberton, R. S. \& Finlayson-Pitts, B. J. Diffuse reflectance infrared studies of the reaction of synthetic sea salt mixtures with $\mathrm{NO} 2$ : A key role for hydrates in the kinetics and mechanism. J. Phys. Chem. A 101, 1277-1286 (1997).

79. Blake, R. S., Wyche, K. P., Ellis, A. M. \& Monks, P. S. Chemical ionization reaction time-of-flight mass spectrometry: Multi-reagent analysis for determination of trace gas composition. Int. J. Mass Spectrom. 254, 85-93 (2006).

80. Hansel, A. et al. Proton transfer reaction mass spectrometry: on-line trace gas analysis at the ppb level. Int. J. Mass Spectrom. Ion Process. 149-150, 609-619 (1995).

81. McNeill, K. \& Canonica, S. Triplet state dissolved organic matter in aquatic photochemistry: reaction mechanisms, substrate scope, and photophysical properties. Environ. Sci. Process. Impacts 18, 1381-1399 (2016).

82. Rosario-Ortiz, F. L. \& Canonica, S. Probe Compounds to Assess the Photochemical Activity of Dissolved Organic Matter. Environ. Sci. Technol. 50, 12532-12547 (2016).

83. McCabe, A. J. \& Arnold, W. A. Reactivity of triplet excited states of dissolved natural organic matter in stormflow from mixed-use watersheds. Environ. Sci. Technol. acs.est.7b01914 (2017). doi:10.1021/acs.est.7b01914

84. Grebel, J. E., Pignatello, J. J. \& Mitch, W. A. Impact of halide ions on natural organic matter-sensitized photolysis of 17B-estradiol in saline waters. Environ. Sci. Technol. 46, 7128-7134 (2012).

85. Zhou, X. \& Mopper, K. Determination of photochemically produced hydroxyl radicals in seawater and freshwater. Mar. Chem. 30, 71-88 (1990).

86. Zhang, Y., Del Vecchio, R. \& Blough, N. V. Investigating the mechanism of hydrogen peroxide photoproduction by humic substances. Environ. Sci. Technol. 46, 11836-11843 
(2012).

87. Garg, S., Rose, A. L. \& Waite, T. D. Photochemical production of superoxide and hydrogen peroxide from natural organic matter. Geochim. Cosmochim. Acta 75, 43104320 (2011).

88. Abdel-Shafi, A. A., Worrall, D. R. \& Wilkinson, F. Singlet oxygen formation efficiencies following quenching of excited singlet and triplet states of aromatic hydrocarbons by molecular oxygen. Photochem. Photobiol. Sci. 133-143 (2001).

89. Lee, M. T. et al. The opposing effect of butanol and butyric acid on the abundance of bromide and iodide at the aqueous solution-air interface. Phys. Chem. Chem. Phys. 21, 8418-8427 (2019).

90. Huang, D. et al. Enhanced Photochemical Volatile Organic Compounds Release from Fatty Acids by Surface-Enriched Fe(III). Environ. Sci. Technol. (2020). doi:10.1021/acs.est.0c03793

91. Pullin, M. J., Anthony, C. \& Maurice, P. A. Effects of iron on the molecular weight distribution, light absorption, and fluorescence properties of natural organic matter. Environ. Eng. Sci. 24, 987-997 (2007).

92. Zhao, J. \& Nelson, D. J. Fluorescence study of the interaction of Suwannee River fulvic acid with metal ions and Al 3+-metal ion competition. J. Inorg. Biochem. 99, 383-396 (2005).

93. Poulin, B. A., Ryan, J. N. \& Aiken, G. R. The effects of iron on optical properties of dissolved organic matter. Environ. Sci. Technol. 48, 10098-10106 (2014).

94. Ciuraru, R. et al. SI: Photosensitized production of functionalized and unsaturated organic compounds at the air-sea interface. Sci. Rep. 5, 1-5 (2015).

95. Shrestha, M. et al. Let there be light: stability of palmitic acid monolayers at the air/salt water interface in the presence and absence of simulated solar light and a photosensitizer. Chem. Sci. 9, 5716-5723 (2018). 
